Article

\title{
Discrimination of Second-Generation Professionals in Leadership Positions
}

\author{
Ismintha Waldring ${ }^{1, *}$, Maurice Crul $^{1}$ and Halleh Ghorashi ${ }^{2}$ \\ ${ }^{1}$ Sociology Department, Erasmus University, 3000 DR Rotterdam, The Netherlands; E-Mails: i.e.waldring@vu.nl (I.M.), \\ crul@fsw.eur.nl (M.C.) \\ ${ }^{2}$ Sociology Department, VU University, 1081 HV Amsterdam, The Netherlands; E-Mail: h.ghorashi@vu.nl \\ * Corresponding author
}

Submitted: 23 January 2015 | In Revised Form: 10 April 2015 | Accepted: 16 June 2015 |

Published: 23 July 2015

\begin{abstract}
This article, based on interviews from the Dutch Pathways to Success Project, investigates how Turkish-Dutch and Moroccan-Dutch second-generation professionals in leadership positions experience and deal with subtle discrimination at work. We argue that subtle discrimination in organizations remains a reality for second-generation professionals in leadership positions. Because organizations are penetrated by power processes in society at large, these professionals are perceived not only on the basis of their position within the organization, but also on the basis of their marginalized ethnic group background. We show this through the existence of subtle discriminatory practices at three organizational levels - that of supervisors, same-level colleagues and subordinates-which may take place at one or more of these levels. When dealing with subtle discrimination, Turkish-Dutch and Moroccan-Dutch second-generation professionals in leadership positions show an awareness of organizational power and hierarchies. This awareness amounts to various forms of "micro-emancipation" by the second generation-adapted to the organizational level (supervisors, same-level colleagues and subordinates) they are dealing with - that question and challenge subtle discrimination in organizations.
\end{abstract}

\section{Keywords}

discrimination; ethnic; leadership; organization; power; second generation; work

Issue

This article is part of a regular issue of Social Inclusion, edited by Professor Ulf R. Hedetoft (University of Copenhagen, Denmark).

(C) 2015 by the authors; licensee Cogitatio (Lisbon, Portugal). This article is licensed under a Creative Commons Attribution 4.0 International License (CC BY).

\section{Introduction}

In March 2015, the Dutch Prime Minister stated in a newspaper article that labour market discrimination in the Netherlands exists, but that he could do nothing about it on a structural level (Metro, 2015). He claimed that migrants and second and third generation descendants of migrants always face opposition and discrimination, no matter where they live and added, rather paradoxically, that the solution to labour market discrimination lies in the hands of those being discriminated against. It is up to them to "fight their way in" (authors' translation) and to not give up.

The Prime Minister's attitude towards a structural injustice in Dutch society signals a context in which the existence of labour market discrimination has only very recently been publicly acknowledged. The Netherlands has long been known for its history of tolerance towards many aspects of social life. And along with this history of tolerance, there has been an assumed absence of racism in Dutch society (Vasta, 2007, p. 715). Even though there have been indications for some time now that discrimination exists in various fields in the Netherlands (Jungbluth, 2010; Siebers, 2010), such as 
the labour market with its higher levels of ethnic minority unemployment, regardless of educational level (Andriessen, Fernee, \& Wittebrood, 2014; Centraal Bureau voor de Statistiek, 2012), the reluctance to address racism and discrimination (Ellemers \& Barreto, 2009; Ghorashi, 2014; Vasta, 2007) remains.

The Dutch labour market context thus seems to be one where assumed self-reliance and agency leave people to fend for themselves when facing discrimination based on their ethnic background, either when trying to enter the labour market or within their organizations. It is within this context that we aim to understand how people experience and deal with discrimination in the workplace. In order to do so, we will focus on the Pathways to Success Project (PSP) interviews with second-generation professionals with a Turkish or Moroccan background, working in leadership positions. They can be seen as the active "gogetters" the Dutch Prime Minister envisions, as they seem to be successfully climbing the corporate ladder.

The PSP interviews are indeed stories of "success". But they also show that discrimination at work occurs, and is often expressed in ways that leave secondgeneration professionals wondering if it is discrimination at all. Moreover, discrimination is perpetrated by supervisors, same-level colleagues and subordinates alike. Our aim is to unravel the ways in which discrimination towards second-generation professionals in leadership positions resonates within different organizational relationships. We therefore pose the following research question: How do Turkish-Dutch and Moroccan-Dutch second-generation professionals working in leadership positions experience and deal with subtle discrimination in different organizational relationships-such as with supervisors, co-managers and subordinates-within an organization?

We want to contribute to the body of literature on discrimination in organizations by showing that discrimination can still affect people who can be considered to "have fought their way in". Discrimination in the labour market or workplace is not only experienced by job seekers or people occupying subordinate positions, but also by those in leadership positions. We will argue that this is partly due to the characteristics of subtle discrimination, which make it difficult to pinpoint certain behaviour or comments as discrimination. It is also due to characteristics of the Dutch context, whereby organizations may be penetrated by power processes in society at large through which ethnic minorities can be marginalized. This penetration may contribute to an organizational climate in which TurkishDutch and Moroccan-Dutch second-generation professionals still face discrimination in the workplace even though they have climbed the corporate ladder into leadership positions.

The structure of the article is as follows. We will first explore the concepts of discrimination, bounda- ries, power and agency. We will then present a methodological overview of our research, followed by an analysis of our interviews. In the conclusion, we will provide an answer to the central question posed in this article.

\section{Theoretical framework}

Discrimination and power are intertwined concepts, and both have blatant and hidden ways of manifesting themselves (cf. Van Laer \& Janssens, 2011). When studying how second-generation professionals in leadership positions experience discrimination in organizations, we therefore explore both concepts theoretically. Furthermore, as discrimination can be seen as both an expression of societal boundaries (cf. Lamont, 2002, p. 243), and a mechanism for reinforcing these boundaries (Van Laer \& Janssens, 2011; Vasta, 2007), we aim to link how discrimination and boundaries can be connected theoretically. Lastly, we will theoretically connect power and agency, as on the one hand, enabling action is inherent to the concept of power (Fleming \& Spicer, 2014, p. 280; cf. Scott, 2008, p. 38), while on the other hand, agency can be limited by organizational structures, such as hierarchy, which are put into place through power.

\subsection{Discrimination, Subtle Discrimination and Boundaries}

Blatant discrimination refers to unequal treatment arising from an explicit belief among individuals that members of certain social groups are inherently inferior (Ellemers \& Barreto, 2009, p. 750). This belief translates into negative treatment of individuals based on their alleged group membership instead of their individual merits (Kloek, Peters, \& Sijtsma, 2013, p. 407). Blatant discrimination is thus reflected in clearly identifiable unfair treatment, leading to visible structural outcomes, such as denial of employment for ethnic minorities (Van Laer \& Janssens, 2011, p. 1205). Yet, this open rejection of individuals based on their group membership is increasingly becoming a thing of the past (cf. Coenders, Scheepers, Sniderman, \& Verberk, 2001; Deitch et al., 2003; Meertens \& Pettigrew, 1997), as discrimination is legally forbidden in many Western countries and publicly spurned.

The fact that blatant discrimination is forbidden and frowned upon does not, however, mean that unequal treatment based on group membership no longer exists. Discrimination has become more subtle (Zick, Pettigrew, \& Wagner, 2008), differing from its blatant predecessor due to its hidden and everyday form. Subtle discrimination can be understood as behaviour "...entrenched in common, everyday interactions, taking the shape of harassment, jokes, incivility, avoidance, and other types of disrespectful treatment" (Van 
Laer \& Janssens, 2011, p. 1205). It pervades everyday situations and is characterized by covertness (Meertens \& Pettigrew, 1997), occurring specifically in situations in which perpetrators can "hide" their intentions, maintaining the image of being non-discriminatory (Ellemers \& Barreto, 2009; Deitch et al., 2003; Van Laer \& Janssens, 2011). This makes subtle discrimination difficult to recognize and address when on the receiving end of it.

The concealed aspect of subtle discrimination points to its institutionalized nature; it reflects "...the covert expression of socially acceptable anti-minority views" (Meertens \& Pettigrew, 1997, p. 57). The social acceptability of these views can lead to a perpetuation of societal differences between people of ethnic minority and native-parentage descent, "fix[ing] the barriers preventing a new generation of skilled and educated minorities to escape their weak [starting-IW] position" (Van Laer \& Janssens, 2011, p.1220).

These barriers can be understood as boundaries, which are social constructs, created in a specific historical, political and social context (Van Laer \& Janssens, 2011, p. 1206). Boundaries function as mechanisms of inclusion and exclusion (Barth, 1994), indicating who belongs within the boundary lines and who does not (Alba, 2005). Boundaries can thus act to maintain structural inequalities, while simultaneously hiding them from the public eye, as they are built-in, unquestioned parts of the system (Vasta, 2007, p. 728). These undisputed parts of the system are exacerbated by predominantly negative public debates and media coverage on ethnic minorities (cf. Kloek et al., 2013, p. 406; Van Reekum \& Duyvendak, 2012; Vasta, 2007, p. 71) and fear of societal changes caused by supposedly unbridgeable cultural differences inherent to "the other" (Ghorashi, 2014).

The hidden and institutionalized way in which subtle discrimination operates doesn't necessarily lead to subtle outcomes (Deitch et al., 2003, p. 1317; Van Laer \& Janssens, 2011; Sue et al., 2007). Moreover, the outcomes of subtle discrimination are more detrimental for some groups than for others (Verkuyten, 2002). Muslims throughout Europe run the greatest risk regarding stereotyping, prejudice, discrimination and social exclusion (Allen \& Nielsen, 2002; Kloek et al., 2013; Van Laer \& Janssens, 2011; Vasta, 2007; Verkuyten, 2002; Zick et al., 2008). This could concern their religion, culture or social position (Foner \& Alba, 2008; Kloek et al., 2013; Vasta, 2007; Verkuyten, 2002).

Subtle discrimination thus results in nearly invisible boundaries being drawn in all layers of society around a specifically targeted group of people, while impeding recognition of these boundaries. This can easily turn into a situation in which people experiencing subtle discrimination-for instance in the workplace-are rendered disempowered to act upon it.

\subsection{Power, Subtle Power and Agency in Organizations}

Power is ubiquitous in organizations (Fleming \& Spicer, 2014 , p. 285). And power, just like discrimination, has both blatant and subtle manifestations, resulting in more and less visible expressions of it (cf. Lukes, 1986). Power can be understood as the ability of a person to intentionally influence the behaviour of other people in line with what is deemed necessary by the person wielding the power (Fleming \& Spicer, 2014, p. 239; Scott, 2008, p. 29). This open power play “...rel[ies] upon identifiable acts that shape the behaviour of others" (Fleming \& Spicer, 2014, p. 240) and results from hierarchy and uneven power distribution (Wilson \& Thompson, 2001, p. 65). Yet, this idea of power only provides a partial explanation when looking at how power in organizations works. Exercising power cannot be solely equated to holding a position of authority. Other, more structural and therefore more concealed and subtle, aspects also play a role (Scott, 2008, p. 29; Fleming \& Spicer, 2014).

Subtle forms of power share a common feature in that they are considered to be structural. This implies that subtle power reaches into the way people think about and reflect upon power dynamics, accepting them not only as a given, but even as constituting the natural order (Foldy, 2002, p. 97). And this "natural order" suggests that for a more complete picture of power, societal structures must also be taken into account (cf. Lukes, 1986; Scott, 2008; Van Laer \& Janssens, 2011). Societal structures, bearing hegemonic beliefs and opinions from larger society, penetrate organizations (Van Laer \& Janssens, 2011, pp. 12061207), making one's societal background relevant in addition to one's organizational function. Organizations can therefore be seen as reflections of broader society, reproducing inequality rather than inventing it (DiMaggio \& Powell, 1983, p. 150).

Van Laer and Janssens (2011) show that societal background indeed reaches into organizations. Their study portrays ethnic-minority professionals who are faced with "...subtle discrimination in the workplace [that] can be understood as micro-expressions of macro-level power dynamics that operate in ambiguous ways and are based on processes of subtle power" (Van Laer \& Janssens, 2011, p. 1219). Their respondents experienced so-called "racial micro-aggressions" (Sue et al., 2007, pp. 275-277), reflecting negative images about the ethnic group with which the professionals are associated, but so subtly that the negative images remain unchallenged and are reproduced (Van Laer \& Janssens, 2011, p. 1214). Moreover, racial micro-aggressions aren't limited to class and can thus equally affect upper-middle class professionals (Van Laer \& Janssens, 2011).

However, employees experiencing subtle power and subtle discrimination in the workplace aren't mere 
passive recipients (Wilson \& Thompson, 2001, p. 75; cf. Ghorashi \& Ponzoni, 2014). People reflect on their circumstances, weighing their ability for successful action, as power not only constrains, but also enables actions (Fleming \& Spicer, 2014, p. 280; Scott, 2008, p. 38). These actions may vary, but their commonality is that when employees decide to act, they are likely to do this by complying with company rules that cannot be bent, while acting as change-agents whenever they see possibilities to do so (Foldy, 2002, p. 97; Zanoni \& Janssens, 2007, p. 1389). This agency can be understood as deliberate action or deliberate inactivity, and it points to employees' ability to "function as...definers, interpreters, and appliers of institutional elements" (Scott, 2008, p. 223).

As opposed to grand forms of social change which have been the kind of agency envisaged in relation to blatant expressions of power, agency vis-à-vis subtle power and subtle discrimination in organizations will not lead directly to large-scale changes. The type of agency which is increasingly utilized against hegemonic normalized structures is "micro-emancipation" (Zanoni \& Janssens, 2007, p. 1377). This type of agency is "fragmentary and temporary" (Zanoni \& Janssens, 2007, p. 1395) rather than containing "successive moves towards a predetermined state of liberation" (Alvesson and Willmott in Zanoni \& Janssens, 2007, p. 1377). As such it is akin to the idea of "tempered radicals" (Meyerson and Scully in Fleming \& Spicer, 2014, p. 275), a term used for employees who "slowly and patiently change the way leaders understand themselves in relation to important social justice issues within the firm" (Fleming \& Spicer, 2014, p. 275). Micro-emancipation enables resisting power, for instance through creating awareness. By exposing the subtleness of power and discrimination in an organization, even if it's only on an individual level, microemancipation might amount to questioning organizational structures. And this could potentially lead to changes beyond the individual level (Zanoni \& Janssens, 2011, pp. 1394-1395), reviewing and reshaping the hegemonic negotiated order (Wilson \& Thompson, 2001, p. 76).

\section{Pathways to Success Project Methodology}

\subsection{The Pathways to Success Project}

The Pathways to Success Project (PSP) is a qualitative study that was conducted in Amsterdam and Rotterdam, the Netherlands. The study was initiated because of earlier findings from TIES $^{1}$, showing that a quarter of

\footnotetext{
${ }^{1}$ TIES stands for The Integration of the European Second generation, a large-scale international study on the second generation in Europe, conducted in eight countries encompassing 15 European cities, during 2007 and 2008
}

the Turkish-Dutch and Moroccan-Dutch second generation is in or has finished higher education. This finding not only opposes the societal tendency to view this group as problematic, it also inspires us to understand how these people have managed to get where they are, taking into account their school trajectories, labour market experiences, and social activities.

We selected respondents on the basis of one of the three criteria we used for defining "success":

1. Having finished higher education (BA and/or MA), or

2. Managing at least five people in a professional occupation, or

3. Earning more than $€ 2000$ net/month.

Through this definition we have tried to objectify the concept of success. Yet, we are aware that success can mean different things to different people, allowing for a different setup of the same study, embedded in a different way of defining the concept. Furthermore, we are aware that by selecting people based on how successful we deem them to be, we are selecting on our dependent variable.

We chose semi-structured interviews for data collection. Because we employed multiple interviewers to cover our sample-size, we needed a fixed questionnaire ensuring that all respondents would be asked the same topics, while simultaneously allowing interviewers the liberty to probe, and interviewees the liberty to address issues beyond the questionnaire (Gomm, 2008, p. 229; Gilbert, 2008, p. 247).

\subsection{Analyzing Discrimination}

We interviewed 40 Turkish-Dutch and Moroccan-Dutch second-generation professionals in leadership positions. The interviews took 60 to 90 minutes, and were voice-recorded and transcribed by the interviewers. The transcripts were subsequently coded by the PSP research team, using the qualitative computer program "Kwalitan".

The coding and analysis of discrimination was sometimes challenging. Respondents seemed reluctant to label their experiences in the workplace as "discrimination". This could have its origin in the specific Dutch context in which talking about discrimination can be seen as claiming the mantle of victimhood (cf. Ellemers \& Barreto, 2009). But it could also be due to the socalled "achievement narrative" (Konyali, 2014), through which successful second-generation professionals try to avoid victimization by emphasizing their individual skills and accomplishments. Talking about discrimination at work seems to run contrary to this achievement narrative, unless it is framed in terms of overcoming discrimination, for instance through hard work and resilience. 
We conducted the analysis using the following steps: firstly, the PSP interview contained one open question on discrimination in organizations in which we stated that discrimination occurs in all organizations and subsequently asked about respondents' experiences. Through this outspoken question we obtained reflections by respondents on work situations in relation to discrimination. These reflections led the majority of the interviewees to talk about situations in which they felt that something wasn't quite right, but they questioned whether these situations could be labelled as "discrimination". Some interviewees explicitly mentioned "subtle discrimination" when talking about these incidents.

Secondly, throughout the interview section on labour market experiences, interviewees referred to work situations in which they felt uneasy about things said or done by others in their organizations. Again, the majority of these examples were accompanied by question marks from the interviewees as to whether it was discrimination they were faced with.

The PSP research team coded the above-mentioned situations as "subtle discrimination", because the descriptions showed commonalities with characteristics of subtle discrimination: often the incidents happened in circumstances which allowed for more than one interpretation of the incident. Moreover, the incidents usually happened during average, seemingly innocent interactions, in which all of a sudden things were said or done that made the interviewees wonder why they felt hurt or unjustly treated.

We consequently grouped these incidents into four categories, as all of the incidents mentioned by the Turkish-Dutch and Moroccan-Dutch second-generation professionals in leadership positions fitted into one of them: 1) missed promotions; 2) jokes; 3 ) comments on and disturbing questions about Muslims and Islam; and 4) questioning of their authority to lead. We are aware that missing out on a promotion or questioning of authority is hardly subtle; however, we labelled them "subtle discrimination" as interviewees mentioned that they only suspected that they had been surpassed or challenged on their authority to lead because of their ethnic background, but could not be sure that this was the case.

The next step in our analysis ascribed instances of subtle discrimination to either a supervisor, a samelevel colleague or a subordinate. This division resulted from the fact that jokes and comments/questions happened at all three levels, but missed promotions were unique to the relationship with supervisors and questioning of authority to lead was unique to the relationship with subordinates. Furthermore, the division also resulted from the fact that the Turkish-Dutch and Moroccan-Dutch second-generation professionals showed different responses depending on which organizational level they were dealing with.

\subsection{The Respondents}

The PSP respondents all come from labour migrant families. The majority of their parents worked in lowskilled jobs after arriving in the Netherlands and had little to no knowledge of the Dutch education system. The Turkish-Dutch and Moroccan-Dutch secondgeneration professionals in leadership positions thus had to pave their own way through school, university and into the labour market, with little instrumental help from their parents (Elitesproject, 2015).

The respondents work in both public (education, government, health care, social work) and private (commercial managers in a bank, business, accountancy, IT and consultancy, and lawyers) sectors. Most respondents work in paid employment. A small minority works as self-employed bosses.

The interviewees consisted of 26 men and 14 women with a mean age of 31 years. The youngest respondents, in paid employment and self-employed leadership positions, are 25 years old and both are men. The oldest respondents in paid employment and self-employed leadership positions are both women, whereby the former is 41 and the latter is 46 years old. We had 20 respondents in leadership positions from Amsterdam and 20 from Rotterdam. Their experiences with subtle discrimination in the workplace will be highlighted in the next section.

\section{Subtle Discrimination in the Workplace}

Subtle discrimination in the workplace is a reality for many of our PSP respondents in leadership positions. They experience subtle discrimination in different organizational relationships and consequently have to deal with supervisors, same-level colleagues and subordinates. These multi-level experiences with subtle discrimination appear to typify the second generation in leadership positions. Their position within the organization goes hand-in-hand with negative opinions in Dutch society about ethnic minorities (Kloek et al., 2013; Van Reekum \& Duyvendak, 2012; Vasta, 2007), permeating organizations (DiMaggio \& Powell, 1983; Van Laer \& Janssens, p. 2011) and rendering the second generation vulnerable to subtle forms of power (Van Laer \& Janssens, 2011, pp. 1206-1207).

As these subtle forms of power are not solely linked to organizational hierarchy but also to hegemonic, built-in and undisputed structures in larger society, the second generation in leadership positions experiences subtle discrimination mainly through being associated with a group bearing negative connotations. They seem to serve as "tokens" by being highly visible in the organization as newcomers in positions of power, and having stereotypes attributed to them by the dominant group, as they are often seen as representatives of their (ethnic) group rather than as individuals (Kanter, 
1977). This renders tokens vulnerable (Benschop \& Doorewaard, 1998), allowing them no room for mistakes. Moreover, in cases where they represent a group with negative connotations, they have to work hard to reverse this image by presenting a good example. And working hard and presenting a good example are indeed strategies used by the PSP respondents.

\subsection{Subtle Discrimination and Agency at the Supervisor Level}

Although subtle discrimination by supervisors occurs, members of the second generation in leadership positions generally feel valued by their supervisors. The majority states that there is room for their ambitions. They discuss these ambitions with their supervisors, to find out what is needed to meet the functional demands for promotion, and how to obtain financial support for additional courses. However, the second generation in leadership positions is a numerical rarity in most organizations, making them highly visible and prone to the token-role (Kanter, 1977). This heightened visibility might lead to above-average performance pressure, possibly explaining their belief that they need to work harder than colleagues from a native parentage background to get ahead in their career. This belief is rooted in the experience of missing out on promotions. Yet, respondents are careful to label a missed promotion as "discrimination", even if being passed over for advancement can have major consequences for their career. This is to be expected, as such a claim is often hard to sustain:

No, I"ve told a colleague that another colleague got promoted and I didn't but I don't have any hard evidence....But like I said, I don't have evidence. In large organizations, these decisions are made behind closed doors. That makes it hard to prove. You can't do anything about it.... had had a very good year [in the organization-IW] but well, what is said is that others were better. You can disagree but there's little point in protesting. (Turkish-Dutch male, IT consultant, Rotterdam)

The only thing I can conclude is that white colleagues get ahead far quicker than coloured colleagues. That's a conclusion I made for myself. (Moroccan-Dutch male, Chief Information Management, Amsterdam)

In addition to withholding promotion opportunities, subtle discrimination by supervisors also comes in the form of jokes. Jokes are made within a context where the second generation in leadership positions are newcomers to a field where the rules of the game have already been set (Keskiner, 2013, pp. 21-22). This, combined with coming from an ethnic and religious group about which negative stereotypes are dominant in society, results in them being targets of discriminatory jokes, as their rare numbers and marginalized group status can set them apart:

I came back from a ski trip. I came back to work after driving for twelve hours and everybody entered the room and one of the partners [in a Law firmIW] saw me and says: "Hey [name respondentIW], my car has been stolen, do you know where it is?" Yes, so you enter the room, ok, and my reaction was: "Well, what kind of car is it? A Volvo? Ah, already on its way to Russia then." Everybody laughing. Those are things that could be considered prejudice and I can't and won't change the way people express themselves. Fine. It's not troubling me. I'm still here and it's not such a big deal.... (Turkish-Dutch male, Lawyer, Amsterdam)

I've had comments by some of the partners [from the Law firm-IW]. And..., it makes you wonder if it's just ignorance, or that...should I place it in a context of discrimination? These things you want to forget. But I do think, I'm a pretty open person, so I joke too, and self-mockery is important. But when someone else takes over the mockery, and pushes it to a limit....That has happened, but not too often. (Moroccan-Dutch male, Lawyer, Amsterdam)

In dealing with subtle discrimination by supervisors, our interviewees employ various forms of agency. Their response to missed promotions is of a subtle nature, whereby they work even harder to achieve their goals. This is an active strategy to counter the disempowerment of feeling surpassed for a promotion because of ethnicity or religion, but they do not explicitly communicate this strategy. They simply do it, expecting it to pay off in the future, as they know their qualities are recognized, even if it takes more effort than with colleagues of native parentage background:

I didn't really notice that I was heavily discriminated....Do other people or ethnic majority people get more chances than I do? Sure. In the beginning, when someone got a promotion and I didn't, then I would think: "why him and not me?" Getting promoted is always [a-IW] subjective [decision-IW]. Perhaps there's only one spot available. You have to work harder, and then you get it. (MoroccanDutch male, Accountant, Rotterdam)

The interviewees respond to jokes by joking back in some cases, confronting their supervisors in other cases or ignoring the jokes altogether. They weigh whether the jokes pose a career threat. When they do respond, they do so through subtly joking back, thereby turning the tables, making use of the organizational 
culture in which jokes are acceptable (cf. Foldy, 2002; cf. Zanoni \& Janssens, 2007):

I have a very quick feeling for it and I know how to bend it into something funny from my part, to prevent an embarrassing moment. Not even for myself but for others. I know that if I want to, I can have him, but I also know that that won't get me anywhere. (Turkish-Dutch male, Lawyer, Amsterdam)

Being denied an upward career move, and contemplating if this is connected to subtle discrimination, is uniquely linked to second generation leaders and their supervisors. Jokes are not. The second generation in leadership positions also faces jokes by colleagues working in similar managerial functions. How does subtle discrimination operate at an equal organizational level?

\subsection{Subtle Discrimination and Agency at the Colleague Level}

Subtle discrimination by colleagues working on the same organizational level comes in the form of jokes, but members of the second generation in leadership positions also feel that they need to justify identity aspects, such as their ethnic or religious background. The pressure to adapt and hide certain aspects of one's identity does not necessarily equal discrimination, but uneasiness prevails. There is a sliding scale; at what point does one take negative remarks by colleagues about religious customs like abstaining from alcohol or wearing a veil personally, or after how many times does being asked about Islamic festivities become annoying? The quote below gives an impression of the sort of situations people have to deal with:

There have been conversations that happened on a personal level. They [co-workers-IW] are talking about something negative and then they start asking you questions, out of the blue. Questions like "do you also have a prayer rug at home?", or "things are done differently in your culture, right?" These are subtle, sometimes insinuating things. I try not to take it too seriously. (Moroccan-Dutch male, Municipality Manager, Amsterdam).

Respondents also talked about same-level colleagues asking questions and posing comments that are not without judgment, as they reflect mainstream negative opinions and debates in the Netherlands concerning Muslims in particular (Van Reekum \& Duyvendak, 2012; Vasta, 2007). The second generation, as presumed representatives of their group (cf. Kanter, 1977), need to account for the behaviour of others, to whom they are only connected through ethnicity or religion. They are no longer addressed as individuals but as spokespeople, supposedly capable of explaining the behaviour of strangers, simply because these strangers come from the same ethnic or religious background:

I remember that there was this ethnic minority individual who had done something, which became a news item. Then colleagues would ask me "What's the matter with this person?" Then I feel like, I don't know this person, he's not my brother. (Moroccan-Dutch female, IT Project Manager, Amsterdam)

Certain conversations happen and you somehow feel it's about you. I have to say, it doesn't happen that frequently in my job. But, sometimes, things are said..., when something is covered by the news, something concerning Islam....So, it's not even that I'm being discriminated but things are said sometimes that are hurtful to you. (Moroccan-Dutch female, Head Service Department, Amsterdam)

The interviewees considered that being held responsible for others' actions on the basis of a shared ethnicity or religious background is a form of discrimination that they cannot really stand up against, since nothing has been said or done against them personally (cf. Verkuyten, 2002). It is in these sort of situations that samelevel colleagues omit identity markers that are more salient for the workplace, while it is precisely these professional identity markers that could advance second-generation acceptance within the organization (Waldring, Crul, \& Ghorashi, 2014; Wimmer, 2008).

Although the nature of the remarks by same-level colleagues make them difficult to respond to, reactions by the second generation are quite explicit. It seems that respondents are less willing to accept these subtle forms of discrimination from their colleagues than from their supervisors. Not only does the second generation joke back harshly when confronted with discriminatory jokes, they also openly confront their colleagues with the stereotypical nature of their comments. They discuss issues, questioning the status quo:

When I even sense something like that [discrimination-IW], I immediately call their remarks into question. Look, for example, I have double nationality. I have a Dutch and a Turkish passport. And every now and then, during lunch, we have a discussion about this. People tell me I should have only one [passport-IW] blabla. Then I asked them: why?... Why, in God's name can I only have one and why should I have to choose between Dutch and Turkish nationality? How am I supposed to make that choice? And then I just bounce it back. I just ask open questions and then you see that they start to think for themselves instead of following the crowd. (Turkish-Dutch male, Commercial Project Manager, Rotterdam) 
When someone makes a nasty comment about veils or something like that, I would be the person to confront them immediately, and not always in the nicest of manners. Because, let's be real, it's mostly the [ethnic-IW] Dutch commenting on the Moroccans. But I retaliate with a range of topics and then it's suddenly quiet. So yes, it is..., of course it's discrimination. And you hear "Muslims this and Muslims that". Then I will be the one stating clearly: "Listen, I'm a Muslim too and I feel addressed [by your comments-IW], and I don't agree with them." (Moroccan-Dutch male, Chief Bailiff, Amsterdam)

Members of the second generation push their possibilities as resisting individuals to the limits at this organizational level, refusing to be treated unfairly. Their individual strategy is a textbook case of micro-emancipation, whereby they not only defend what is important to them personally but also aim to change their colleagues" attitudes and behaviours concerning ethnic minorities in general or Islam, more so than when they are dealing with their supervisors (cf. Zanoni \& Janssens, 2007).

The negative discourses on ethnic minorities in the Netherlands clearly resonate within organizations. This is not limited to supervisors and same-level colleagues. Second-generation professionals in leadership positions also experience subtle discrimination by subordinates.

\subsection{Subtle Discrimination and Agency at the Subordinate Level}

Questioning of authority to lead plays a prominent role at the level of subordinates. Members of the second generation in leadership positions describe various experiences with subtle discrimination by subordinates. What these cases share is scrutiny by employees of the capabilities of their second-generation supervisors. These supervisors are among the first from their ethnic group to hold positions of power in organizations, and this poses a sharp contrast to the overall division of power in society, where marginalization mostly befalls those of Turkish and Moroccan descent (Kloek et al., 2013; cf. Slay \& Smith, 2011; Verkuyten, 2002). The negative stereotypes associated with their ethnic and religious group lead to a situation in which members of the second generation in leadership positions cannot afford any error and permanently have to show they possess leadership skills. They therefore emphasize that their leadership role has to be earned, as their subordinates feel reservations about them. Such reservations are less common if managers are from a nativeparentage background:

The acceptance, they [employees-IW] do accept it. But there is, as a figure of speech, some sort of runup period, a period in which people simply have to get used to the fact that you're of Moroccan de- scent, that you've had a certain education and, yes, that you will have to tell them what to do. It takes a while, and I think it takes a while longer than with others. (Moroccan-Dutch male, Lawyer, Amsterdam)

I came across someone whom I had to supervise, well, he was older than me. And he thought: "I'm older, and you're supervising me?" I could tell that he didn't listen to me. On top of that came my Turkish background.... He would make jokes. Just a little, not really offensive but always directed towards Turks and Moroccans. (Turkish-Dutch male, Coordinator Test engineer, Amsterdam)

When it comes to subordinates, the second generation is most cautious in their dealings with subtle discrimination. They address prejudice and stereotypes by their employees but they try to refrain from getting into an open power play with people who they already surpass in rank. Moreover, they try to gain acceptance by showing their employees that stereotypes and prejudice are not applicable to individuals, thereby circumventing "role entrapment", through which they are "forced...into playing limited and caricatured roles in the system" (Kanter, 1977, p. 980). Their nonconformance to stereotyped roles does not come through distancing themselves from their ethnic group (cf. Konyali, 2014), but through finding common ground with the ethnic-majority group based on their professional identity and their competences as "good managers" (Waldring et al., 2014).

I think it is very difficult to gain acceptance. Respect is something you have to earn, and the way to do this is by setting goals together. Setting goals that are manageable and realistic, and trying to reach them together.... When you do this often enough, then you know how the work is going and you're involved with your team at the same time. Just keep on communicating with them. (MoroccanDutch male, IT Consultant, Rotterdam)

Yes, it's about the skills you possess.... Not to brag, but I'm better at communicating than all the other guys here. If I hadn't been, and I had been just a manager and not a salesperson myself, they would have eaten me alive. You have to show them every day that you're better than they are [at the jobIW]. (Moroccan-Dutch male, Chief Social Worker, Rotterdam)

This choice of profiling their professional identity shows that identity can be seen as situational. Yet, "how we self-identify is only part of the equation" (Jenkins in Foldy, 2002, p. 98) and self-identification can be limited by how others perceive us (Van Laer \& 
Janssens, 2014). Therefore, validation of our identity by others is required (cf. Wimmer, 2008, p. 1035). And although this validation sometimes comes over time, when it comes, the second generation in leadership positions runs the risk of merely being seen as "exceptions to the rule", setting them apart from their ethnic group while the negative stereotypes about the entire group remain (Van Laer \& Janssens, 2011).

\section{Conclusion}

The concept of power is important when considering how Turkish-Dutch and Moroccan-Dutch secondgeneration professionals in leadership positions experience and deal with subtle discrimination in the workplace. We will firstly argue that hegemonic, "hidden" power plays a role in understanding how experiences with subtle discrimination continue to be a reality for the second generation in leadership positions from the Pathways to Success Project. Secondly, we will indicate how dealing with these experiences takes into account the more "open", hierarchic power dynamics that are present in organizational hierarchies.

\subsection{Subtle Discrimination and Hegemonic Power}

The Turkish-Dutch and Moroccan-Dutch secondgeneration professionals in leadership positions from the PSP are faced with subtle discrimination at various organizational levels. The expressions of subtle discrimination by supervisors, same-level colleagues and subordinates differ to some extent, but patterns from larger society penetrate organizations at all three levels. The Turkish-Dutch and Moroccan-Dutch secondgeneration professionals in leadership positions experience missed promotions, jokes, comments, questions and challenges to their authority, not necessarily based on their individual performance or behaviour, but on their ethnic and religious group membership. They have to deal with subtle discrimination because they are seen as part of a group that currently holds a marginal position in Dutch society. This societal marginalization, that is obviously not applicable to the second generation in leadership positions from PSP (cf. Van Laer \& Janssens, 2011), wrongly comes to the fore in organizational interactions, leading to situations and interactions in which their organizational role is sometimes overshadowed by their alleged societal background (cf. DiMaggio \& Powell, 1983, p. 150).

These interactions make it clear that hidden, hegemonic power is in operation, leading to the perpetuation of subtle discrimination, even when people manage to reach leadership positions. This hegemonic power is systemic, in the sense that it is part of societal structures and discourses that remain largely unquestioned in daily life (Vasta, 2007). Yet, although this power is unquestioned, it does not go unnoticed as it causes structural inequalities in society (Van Laer \& Janssens, 2011; Deitch et al., 2003) that are reflected in organizational life (Siebers, 2010; Van Laer \& Janssens, 2011), so that subtle discrimination remains a reality for the Turkish-Dutch and Moroccan-Dutch secondgeneration professionals in leadership positions.

\subsection{Agency and Hierarchy}

Turkish-Dutch and Moroccan-Dutch second-generation professionals in leadership positions act upon subtle discrimination at all three organizational levels. They do so in a variety of ways. This difference in reactions comes to the fore most clearly in the case of jokes, as supervisors, same-level colleagues and subordinates alike employ this type of subtle discrimination. The reactions by second-generation professionals to jokes seem to reflect a consideration of the organizational hierarchies, rather than a consideration of the type of subtle discrimination. They appear to weigh up who they are dealing with in order to establish how they should respond to subtle discrimination. Subtle discrimination is confronted most openly when it comes from same-level colleagues. But in the two cases where authority and hierarchy are more obvious, namely supervisors and subordinates, Turkish-Dutch and Moroccan-Dutch second-generation professionals in leadership positions keep their responses subtle. They don't openly challenge either their supervisors, or their subordinates, but rather opt for a subtle joke back, a oneon-one talk or they push their organizational identity to the fore (cf. Waldring et al., 2014; cf. Wimmer, 2008).

This awareness of and dealing with organizational hierarchies and power in the face of subtle discrimination, shows how Turkish-Dutch and Moroccan-Dutch second-generation professionals in leadership positions reflect on their organizational context. They wield their power in different relationships of authority, employing various forms of agency to fit with the situation and people they are dealing with. In the case of supervisors and subordinates, they act as "tempered radicals" (Meyerson and Scully in Fleming \& Spicer, 2014, p. 275) who slowly work their way towards changing opinions, even if it's just on an individual level. With their samelevel colleagues, the confrontations are more open, but still on an individual level. These confrontations most likely will not lead to large-scale changes within the organization, but they constitute an example of microemancipation through which second-generation professionals attempt to create awareness among their colleagues that judging people based on their group membership is unfair and that certain beliefs about ethnic minorities are based on prejudice.

The Dutch Prime Minister's principle of "fighting your way in" as the key to overcoming labour market discrimination, can be challenged. We have tried to show in this article that subtle discrimination can still af- 
fect second-generation professionals in leadership positions because systemic inequalities permeate various organizational relationships. They are faced with hegemonic power that can lead to situations in which their organizational position is overruled by their marginalized ethnic background, rendering them vulnerable to subtle discrimination despite their position of authority.

How Turkish-Dutch and Moroccan-Dutch secondgeneration professionals in leadership positions deal with these exclusionary acts involves an awareness of organizational hierarchies. On the one hand, their possibilities to act as change-agents are limited. This is mainly due to the multiple layers of exclusions they are dealing with in their daily professional settings, as well as the organizational hierarchies they have to take into consideration when addressing subtle discrimination. On the other hand, their awareness of organizational power and hierarchies is used for forms of micro-emancipation, through which they deal with subtle discrimination in different ways, depending on whom they are confronted with. This awareness and subsequent custom-made agency cannot be expected to resolve subtle discrimination in the workplace, but it could possibly hold the key to questioning and challenging hegemonic power structures and relationships in organizations.

\section{Acknowledgments}

The authors would like to thank the reviewers for their valuable comments and suggestions for the paper.

\section{Conflict of Interests}

The authors declare no conflict of interests.

\section{References}

Alba, R. (2005). Bright vs. Blurred boundaries: Secondgeneration assimilation and exclusion in France, Germany, and the United States. Ethnic and Racial Studies, 28(1), 20-49.

Allen, C., \& Nielsen, J. S. (2002). Summary report on Islamophobia in the EU after 11 September 2001. Vienna: European Monitoring Centre on Racism and Xenophobia.

Andriessen, I., Fernee, H., \& Wittebrood, K. (2014). Ervaren discriminatie in Nederland. Den Haag: Sociaal Cultureel Planbureau.

Barth, F. (1994). Enduring and emerging issues in the analysis of ethnicity. In H. Vermeulen \& C. Govers (Eds), The anthropology of ethnicity: Beyond "ethnic groups and boundaries" (pp. 11-31). Amsterdam: Spinhuis.

Benschop, Y., \& Doorewaard, H. (1998). Covered by equality: The gender subtext of organizations. Organization Studies, 19(5), 787-805.

Centraal Bureau voor de Statistiek (2012). Jaarrapport
Integratie 2012. Den Haag/Heerlen: Centraal Bureau voor de Statistiek.

Coenders, M., Scheepers, P., Sniderman, P. M., \& Verberk, G. (2001). Blatant and subtle prejudice: Dimensions, determinants, and consequences; some comments on Pettigrew and Meertens. European Journal of Social Psychology, 31, 281-297.

Deitch, E. A., Barsky, A., Butz, R. M., Chan, S., Brief, A. P., \& Bradley, J. C. (2003). Subtle yet significant: The existence and impact of everyday racial discrimination in the workplace. Human Relations, 56(11), 1299-1324.

DiMaggio, P. J., \& Powell, W. W. (1983). The iron cage revisited: Institutional isomorphism and collective rationality in organizational fields. American Sociological Review, 48, 147-160.

Elitesproject. (2015). Elitesproject.eu. Retrieved from http://www.elitesproject.eu/publications/reports

Ellemers, N., \& Barreto, M. (2009). Collective action in modern times: How modern expressions of prejudice prevent collective action. Journal of Social Issues, 65(4), 749-768.

Fleming, P., \& Spicer, A. (2014). Power in management and organization science. The Academy of Management Annals, 8(1), 237-298.

Foldy, E. G. (2002). Managing diversity: Identity and power in organizations. In I. Aaltio \& A. J. Mills (Eds), Gender, identity and the culture of organizations (pp. 99-112). London, New York: Routledge.

Foner, N., \& Alba, R. (2008). Immigrant religion in the US and Western Europe: Bridge or barrier to inclusion? International Migration Review, 42(2), 360-392.

Ghorashi, H., \& Ponzoni, E. (2014). Reviving agency: Taking time and making space for rethinking diversity and inclusion. European Journal of Social Work, 17(2), 161-174.

Ghorashi, H. (2014). Racism and "the ungrateful other" in the Netherlands. In P. Essed \& I. Hoving (Eds), Dutch racism. Amsterdam: Rodopi.

Gilbert, N. (2008). Researching social life. London: SAGE Publications.

Gomm, R. (2008). Social research methodology: A critical introduction. New York: Palgrave Macmillan.

Jungbluth, P. (2010). Onverzilverd talent II. Utrecht: FORUM.

Kanter, R. M. (1977). Some effects of proportions on group life: Skewed sex ratios and responses to token women. The American Journal of Sociology, 82(5), 965-990.

Keskiner, E. (2013). Generation in transition: Youth transitions among native-born descendants of immigrants from Turkey. (Unpublished Doctoral dissertation). University of Amsterdam, Amsterdam, the Netherlands.

Kloek, M., Peters, K., \& Sijtsma, M. (2013). How Muslim women in the Netherlands negotiate discrimination during leisure activities. Leisure Sciences: An Inter- 
disciplinary Journal, 35, 405-421.

Konyali, A. (2014). Turning disadvantage into advantage: Achievement narratives of descendants of migrants from Turkey in the corporate business sector. New Diversities, 16(1), 107-121.

Lamont, M. (2002). The dignity of working men. Morality and the boundaries of race, class and immigration. Cambridge: Harvard University Press.

Lukes, S. (1986). Power: A radical view. New York: New York Press.

Meertens, R. W., \& Pettigrew, T. F. (1997). Is subtle prejudice really prejudice? The Public Opinion Quarterly, 61(1), 54-71.

Metro (2015). Metro.nl. Retrieved http://www. metronieuws.nl/binnenland/2015/03/liever-eendode-terrorist-dan-een-dode-onschuldige

Scott, J. (2008). Modes of power and the reconceptualization of elites. Sociological Review, 56(s1), 27-43.

Scott, W. R. (2008). Lords of the dance: Professionals as institutional agents. Organization Studies, 29(2), 219-238.

Siebers, H. (2010). The impact of migrant-hostile discourse in the media and politics on racioethnic closure in career development in the Netherlands. International Sociology, 25(4), 475-500.

Slay, H. S., \& Smith, D. A. (2011). Professional identity construction: Using narrative to understand the negotiation of professional and stigmatized cultural identities. Human Relations, 64(1), 85-107.

Sue, D. W., Capodilupo, C. M., Torino, G. C., Bucceri, J. M., Holder, A. M. B., Nadal, K. L., \& Esquilin, M. (2007). Racial microagressions in everyday life. Implications for clinical practice. American Psychologist, 62(4), 271-286.

van Laer, K., \& Janssens, M. (2011). Ethnic minority professionals' experiences with subtle discrimination in the workplace. Human Relations, 64(9), 1203-1227.

van Laer, K., \& Janssens, M. (2014). Between the devil and the deep blue sea: Exploring the hybrid identity narratives of ethnic minority professions. Scandinavian Journal of Management Studies, 30(2), 186-196.

van Reekum, R., \& Duyvendak, J. W. (2012). Running from our shadows: The performative impact of policy diagnoses in Dutch debates on immigrant integration. Patterns of Prejudice, 46(5), 445-466.

Vasta, E. (2007). From ethnic minorities to ethnic majority policy: Multiculturalism and the shift to assimilationism in the Netherlands. Ethnic and Racial Studies, 30(5), 713-740.

Verkuyten, M. (2002). Perceptions of ethnic discrimination by minority and majority early adolescents in the Netherlands. International Journal of Psychology, 37(6), 321-332.

Waldring, I., Crul, M., \& Ghorashi, H. (2014). The fine art of boundary sensitivity. Successful second generation Turks and Moroccans in the Netherlands. New Diversities, 16(1), 71-87.

Wilson, F., \& Thompson, P. (2001). Sexual Harassment as an exercise of power. Gender, Work and Organization, 8(1), 61-83.

Wimmer, A. (2008). Elementary strategies of ethnic boundary making. Ethnic and Racial Studies, 31(6), 1025-1055.

Zanoni, P., \& Janssens, M. (2007). Minority employees engaging with (diversity) management: An analysis of control, agency, and micro-emancipation. Journal of Management Studies, 44(8), 1371-1397.

Zick, A., Pettigrew, T. F., \& Wagner, U. (2008). Ethnic prejudice and discrimination in Europe. Journal of Social Issues, 64(2), 233-251.

\section{About the Authors}

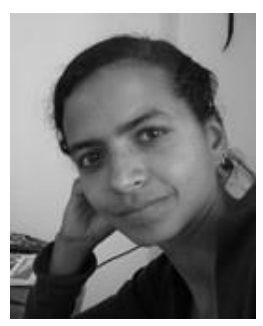

\section{Ismintha Waldring}

Ismintha Waldring studied Social and Organizational Psychology at Leiden University. She is a PhD researcher on the "ELITES: Pathways to Success Project" at the Faculty of Social Sciences, Erasmus University Rotterdam. She is currently working on an international comparative study in four European countries: The Netherlands, Germany, France and Sweden. For this project, interviews have been conducted with second generation professionals of Turkish descent, who are highly educated and working in leadership positions in the Education sector.

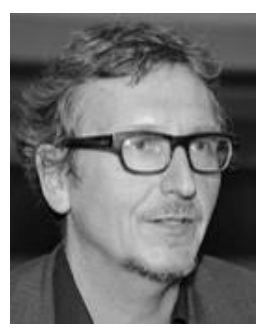

\section{Dr. Maurice Crul}

Maurice Crul is a Professor in Sociology at the Free University in Amsterdam and the Erasmus University of Rotterdam. His research focuses especially on the effect of national and local institutional arrangements in education and the labour market on school and labour market careers of children of immigrants. Crul is the lead author of several books, including Superdiversity. A New Vision on Integration (2013), The Changing face of World Cities (2012) and The European Second Generation Compared (2012). Crul coordinated the TIES project and is currently coordinating the ELITES project. 


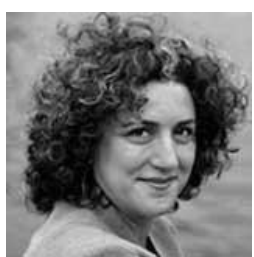

\section{Dr. Halleh Ghorashi}

Halleh Ghorashi is Full Professor of Diversity and Integration in the Department of Sociology at VU University Amsterdam. She is the author of Ways to Survive, Battles to Win: Iranian Women Exiles in the Netherlands and the United States (2003) and co-editor of Paradoxes of Cultural Recognition: Perspectives from Northern Europe (together with S. Alghasi and T. H. Eriksen, 2009) and Muslim diaspora in the West: Negotiating Gender, Home and Belonging (with Haideh Moghissi; Surrey, 2010). 